\title{
An Overview of Dynamic Assessment in the language Classroom
}

\author{
Hussein Meihami $^{1, *}$, Bahram Meihami $^{2}$ \\ ${ }^{1}$ Department of English Language Teaching, Ghorveh Branch, Islamic Azad University, Ghorveh, Iran
}

${ }^{2}$ Department of Accounting, Ghorveh Branch, Islamic Azad University, Ghorveh,

*E-mail address: hussein.meihami99@gmail.com

\section{ABSTRACT}

The purpose of this paper is to outline the recent researches Dynamic ent (DA) in second language learning classroom. As an approach to assessme $\lambda$ an vstruction, A derived from Vygotsky's theory of Zone of Proximal Development (ZPD). Th his ou ing study the very recent researches, which were done in relation with DA and 7 , ave been stigated. This study includes six sections. Section one has focused on an intr duction about the ssence of DA and ZPD. Section two defines specifically about DA and how it is lated to teaching. Section three focuses on the relationship between DA and ZPD. Section four icates asp cts of DA and its effect on Corrective Feedback. Section five is devoted to DA and th ation and differences with Formative Assessment. Finally, section six is all about nclusion or these five mentioned sections. By analyzing and investigating the recent researche thrs beyconfirmed that DA should be entered into L2 classrooms.

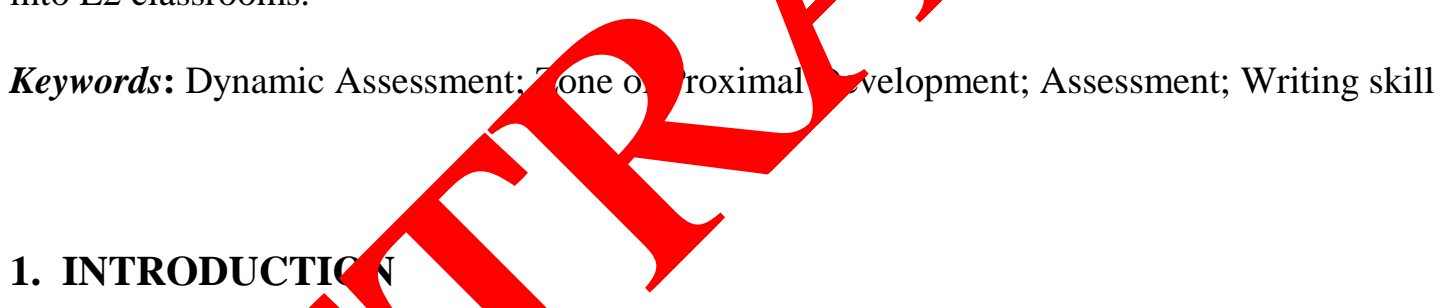

Accordir $g$ to antolf, "th field of second language acquisition (SLA) has reached a point where vers y dep rtments, professional organization, and scholarly journals devoted to supporting a dissem lating research relevant to its aims have recently celebrated a numb - urden nd anniversaries" (Lantolf et al, 2010). On the other side of this, "the fie cont ues to itness debates over fundamental epistemological assumptions that und "d question and methodologies"; see Firth and Wagner (1997) as well as Laffor 2007). The discipline's contested theoretical foundation also explain in part of reluctance / many SLA researches to articulate implications of their work for second language teaching Lafford (2007). As Latoff (2010) has stated, "there is a widespread sentiment among those conducting theoretically informed SLA research that connections to teaching practice is premature" (Lightbown, 200; Gass \& Mackey, 2007).

The Russian psychologist L.S. Vygotsky - whose sociocultural theory of mind (SCT) continues to draw attention from L2 researchers - confronted a similar set of questions as he endeavored to articulate a scientific psychology that offered a coherent perspective on human consciousness while also providing concrete proposals for education (Lantolf et al, 2010).However, as Lantolf (2010) argues, Vygotsky’s dialectical perspective on human 
beings and their relation to the world led him to view these not as separate aspects of his professional work but as complements of one another (Kristen Nielsen, 2012).

Vygotsky insisted that the true test of theory is not in its explanatory power but in its potential to bring about change in the world (Vygotsky, 1997). According to him, his interest was in a psychological theory 'which attempts not so much to explain the mind but to understand and master it' (p. 305), noting also that such a theory 'gives the practical disciplines a fundamentally different place in the whole structure of the science' (p. 305). That is, Vygotsky's scientific enterprise was concerned with much more than a description of human psychology because the kind of understanding he sought was one that illuminotad the processes of the mind's development, specifically the social and cultural means thin which individuals come to master thought.

Vygotsky's promise to praxis runs through every aspect of his york, perha its most well known expression comes in his formulation of th zone of axiral development (ZPD). Much has been written about the ZPD as a len rroug vhich view development. Indeed, the ZPD represents a powerful way of this about oth the products of past development - the development that has be n compl at ne present and that can be inferred from an individual's independent pe io ance - as 1 as cognitive functions that have not yet fully developed but are ill in process of forming (Vygotsky, 1978, p. 86). However, Vygotsky assign a war mor mortant role to the ZPD than simply a theoretical lens, locating it at he center of deyclopmental pedagogy. The significance of the ZPD is that it provides a ramework for the diagnosis of learner abilities and an orienting basis for intervention upport t/eir development. In other words, it is a means of accessing and at the-ame time process of development rather than focusing on its product, as in more conventional approaches to assessment (Kristen Nielsen, 2012). In the d cad's owing Vygotsky's death, use of the ZPD for diagnosis and intervention inspire a number of pedagogical reforms within Russia and internationally (Ko allin Gindi 2007). One line of research that has been particularly fruitful is dyna asse sment (lenceforth, DA). DA has been pursued by school and clinical psych gis s a m.... of more accurately assessing an individual's potential for future dey spment by bedding instruction in the assessment process itself (Sternberg \& Grigor nko, '02). Ech ng Vygotsky's sentiments about the value of theory, Reuven Feuerstei - lead proponent of DA - explains that in DA 'what is at stake is not theoretical -egance, but is as that affect the lives and destinies of real people' (Feuerstein et al., 1 , p. ?

Accordh 0 Hay bod and Lidz (2007) most current approaches to DA are compri of th stages: a conventional assessment of the abilities in question, an inte ventio targetis problematic aspects of learner performance, and a final assessment tha ra the hitial one. Pre- and post-intervention levels are compared, and the differc is taken as an indicator of whether the abilities being assessed lay within the individua PD. Often these insights then lead to more long-term instructional plans. The problem with this approach, however, is that it is more biased toward product than process. Research on L2 DA, in contrast, has focused more directly on the classroom and how mediator-learner interactions can function simultaneously to understand and promote learner development (e.g. Poehner, 2007, 2008). In other words, assessment and instruction exist in a dialectical relation as the provision of mediation attuned to the ZPD allows for the identification of emergent abilities and at the same time supports their development. To date, L2 DA research has not focused on implementation of the procedure during regular classroom instruction but has instead occurred in one-to-one sessions 
outside the classroom and has been implemented by a teacher/researcher with expertise in applied linguistics. Moreover, this research has been conducted in university settings (e.g. Ableeva, 2008).

\section{DEFINING DYNAMIC ASSESSMENT}

Although DA has its roots in Vygotsky's concept of the ZPD, Vygotsky himself did not use the term DA when formulating his proposals on the cultural development of the individual nor when discussing his views on the importance of distinguish ig ben diagnostic and prognostic testing in the school and in the laboratory setting antolf et 2010). In a paper published more than forty years ago, however, A.R. Lyia (1), one Vygotsky's most influential colleagues, contrasts 'statistical' with 'dy' amic' app thes to assessment (p. 7). The former, according to Luria, although grounder sour psych etric principles, inappropriately assumes that a person's solo perform ce test re esents a complete picture of the individual's capabilities. The latter, on ne other d, ar sues that a full picture requires two additional bits of information: no erson's p ormance with assistance from someone else and the extent to whicb pen can benefit from this assistance not only in completing the same task or os, ut in tra cring this mediated performance to different tasks or tests (Kristen Niels h, 2012).

In the preface to their critical review of the 1 earch on DA since the time of Luria's publication, Sternberg and Grigorenko (2002: vii) de DA as a procedure whose outcome: takes into account the results of an interver In this im rention, the examiner teaches the examinee how to perform better on individuc tion the test as a whole. The final score may be a learning score representing the $a \mathrm{fe}$ ence, setween pretest(before learning) and posttest (after learning) scores, or y be the score on the posttest considered alone.

According to Lantolf 20 , "altho gh scholars working in either DA or more traditional psycho-metric Pro. ssment might quibble with this definition, it seems clear that the fy tamental ference between the two approaches has to do with whether or not the din tration o, ne assessment should have the expressed goal of modifying learner ne corma during the assessment itself." DA, because of the fact that has much in comm in in the ZPD, sts that any assessment that fails to determine the extent to which the $\mathrm{p}$ on's rformance is modifiable is incomplete. Nevertheless, if one examins Traditiona s cally sed assessment, due to the accountability of psychometric princip cons cha ge in the person's performance during the administration of the asse smen as a th to these principles, in particular, test reliability (see Lidz, 1991; Has

\section{DYNA IC ASSESSMENT AND ZONE OF PROXIMAL DEVELOPMENT}

For Vygotsky, the notion of praxis was not an ideological position in academic debates but was a powerful orienting basis for his empirical research and clinical work with individuals experiencing learning difficulties and an array of mental disorders (see Vygotsky, 1993). As Kinard \& Kozulin (2008) explained, education plays a crucial role in Vygotsky's theory of development because formal schooling offers the possibility to integrate abstract, theoretical knowledge with everyday experience leading to full conceptual 
understanding of the world. According to these authors, this development occurs through mediation in the form of cultural artifacts, interaction with others, and participation in socially organized activities. However, Vygotsky himself did not articulate or endorse sets of teaching and assessment methods or techniques to be followed in a specified way. Rather, one cannot deny his educational contributions that may be described as helping teachers to reorient their practice to the goal of supporting learners' development of conceptual understanding of the world so that they may position themselves to act in the world in more agentive ways (Kristen Nielsen, 2012).

On this fact we can say that Vygotsky understood that the particular wows in which curricula could be organized to foster development could not be prescr. oed bo hand but needed to emerge as the theory was brought into classrooms. He al as stated Lantolf 2010, understood that this process was necessary for further elabol of tl theory itself, a point exemplified by the evolution of the ZPD concept $\mathrm{n}$ his ow ritin ss. Initially proposed as an alternative to conventional IQ tests, the ZPD is first gmed ative to the school curriculum, with development understood as the dif are setweer earners' current performance and the level demanded by the school. In this way, ZP's provided an indication of time and resources that might be needed o ve indivic as toward set curricular standards.

However, it also defined development in teleolo, tear erms, as arriculum could be viewed as an endpoint, at least at a given grade levf. In this regard, Yygotsky (1933, p. 53, cited in van der Veer \& Valsiner, 1991, p. 341) fo d that some learners were able to 'run through' their ZPD before others, effectively meet the schor l's performance goals more quickly than other learners. In other wards, the as construed as a way of understanding learner progression from on pulum - defined point to another.

This, however, poses the logical quest in $g$ to responsibly support learners who reach the standard ahead of otherc In sub quent/discussions of the ZPD, Vygotsky's statements of its 'great practical gnin nce' to tucation are decidedly non-teleological, as he explains that the ZPD sery on ent instraction to have an optimal role in guiding development (Vygotsky, 98, 20, ad points out that there is no endpoint to development through cy ral mean indis, 2003, p. 204). As some mentioned,Praxis is also a strong current rup ing rough mu in of the pedagogical work pursued by Vygotsky's colleagues and strects, mo notably Piotr Gal'perin (1989) and Vasily Davydov (2004). These scholars aesigned educa al approaches based on Vygotsky's theory that have led to advances in dersta ing of concept formation and internalization. With regard to the ZPD, Valsiner and er Veen 1993) enumerate several strands of Vygotsky-inspired work that have le devel ent in the concept itself, including DA.

The point ou nowever, that there is a good deal of variability among approaches to $\mathrm{BA}$, th maintaining a stronger connection to Vygotsky than others. As we have argued elsewh (Lantolf \& Poehner, 2004, 2007), all DA proponents share a conviction that independ serformance is insufficient to fully understand abilities and that important insights in 6 development are gained when mediation is offered as performance begins to break down. Nevertheless, DA practices differ widely with regard to the quality of mediation they propose as well as how DA sessions relate to ongoing instruction (Kristen Nielsen, 2012).

\section{DYNAMIC ASSESSMENT AND CORRECTIVE FEEDBACK}

As a debatable topic in SLA, corrective feedback is the out of the iceberg, and when it 
is mixed with DA it is going to be much more controversial. There is an extensive research literature on the effects of feedback on L2 learning. A thorough review of this research is well beyond the scope of the present article (for excellent reviews, see Ellis, 2008; Ellis et al., 2009). However, it is useful to relate mediator-learner interaction during DA with the findings and assumptions on feedback as reflected in SLA research. The focus of most SLA research on feedback has been on whether implicit or explicit feedback is more effective in stimulating L2 development (Kristen Nielsen, 2012).

According to Ellis (2008, p. 804, Cited in Lantolf et al, 2010 ) the research shows that teachers use different types (i.e. direct or indirect) and frequency of feedback, depending on such factors as context, personal preference, and recommendations made in their te. education courses. Research has documented, for instance, that teachers quently u recasts to provide learners with indirect correction (Ellis, 2008). One of the ertainti associated with recasts is whether or not they result in acquisition. Whice research rep ort frequent learner uptake of teacher recasts (most often as repetition of corre fon this in itself does not necessarily confirm acquisition. One would war to ment a propriate use of the corrected form in future independent performanc (Ellis, $p, p$ 256). The evidence we present below documents such performance.

In a research conducted by Meihami(2013) on the an ct of in writing grammatical accuracy improvement of advanced EFL students he oun that gi $\mathrm{CF}$ in a direct way has the most effective way of improving the accura of grammaticalpoints. In his research he has declared that CF in the way of DA can be ve beneficial.

On this ground of idea, researchers have als ried to d termine whether corrective feedback better serves acquisition if it is dalivered in, as with recasts, or explicitly as when overtly pointing to an error, corn and perhaps offering a meta-linguistic explanation as well. Ellis et al. (2009) surve ed 1es that directly compare implicit to explicit corrective feedback and conclude th the latter is more advantageous, at least as far as production is concerned $\mathrm{C}^{\mathrm{C}} \mathrm{SI}_{4}$ On the ther hand, these same authors note that some studies report no advantage fo her ty se of feed oack. They also point to research findings that support positive effects fo vp com on when compared to learners who received no feedback at all (p. 315)

Ellis et al. (200 su sted that $r$ is difficult to arrive at unequivocal conclusions with regard to feedb? directly comp able For one $\mathrm{mg}$, some of the studies are experimental, while others are obsery nal; another, measures of learning ranged from mechanical to communicativ avities ad varied with regard to whether focus was on input or output proces Abo 911 , ne studies did not often jibe with respect to what constituted imp icit explic eedback. In most, though not all cases, the former comprised reca al repetition were also used and at times recasts were combined with ctions or repetitions (p. 313). Explicit feedback also varied, ranging from a simple ation that an error occurred to specifying the error accompanied by extensive meta-lingu stic explanation (Kristen Nielsen, 2012).

In another study, Ellis et al. (2009) carried out their own study with groups of lowintermediate proficiency ESL learners where they compared the effects of implicit (recasts) with explicit (repetition of error followed by meta-linguistic information) feedback on learning the past tense -ed marker in English. Without going into detail, and despite selfadmitted limitations, the results of post-tests and delayed post-tests showed a distinct advantage for the group receiving explicit feedback (p. 327).

The authors hypothesize that 'explicit feedback seems more likely to promote the 
cognitive comparison that aids learning' (p. 330). In an earlier study comparing implicit and explicit feedback, Carroll and Swain (1993) speculated that explicit correction aids learning by identifying the site and nature of the learning problem whereas implicit feedback expects learners to infer both of these important aspects of learning.

Based on such findings, one might indeed conclude that explicit corrective feedback is more effective and therefore should be the preferred approach to dealing with learner errors. From a perspective that looks more at the product rather than the process of learning, this makes sense. For instance, if the instructional aim is simply to help learners arrive at a correct response, then explicit feedback is certainly an efficient means. How - aur as Aljaafreh and Lantolf (1994) argued, if the intention is to promote development ien pro s must be foreground, as in the ZPD. This is because development is only abo appropriate performance but it is equally about where responsibility ap con for t performance resides. Development moves from other-regulatio - who on s performance is primarily controlled by someone else - to self gulati who one establishes control over one's own performance. From a Vygotski p $p_{c}$ ctive, th is what learner agency and autonomy are about. By providing uniform e plicit con ive fedback all learners are treated in the same way regardless of the $1 /$ control cy may have
achieved over a particular language feature (Kristen Niel

Consequently, it is difficult to determine how moner gaining over her or his performance and thus much of the pro ess of development not only remains hidden but it may very well be inhibited. Learners ay come to ely on others rather than on themselves, or at least may do so for a longer time pe than ne essary.

\section{DYNAMIC ASSESSMENT AND FORN AT SSESSMENT}

Formative assessment is ofto positio ed in contrast to summative assessment. Summative assessment evalu2 verf mance a the end or the beginning of a unit of study, a course, or a program and fte eurposes of accountability, admission decisions; promotion and selection see d'Ang n et al., 1990; Torrance and Pryor, 1998). While our focus here is on FA we struck the general assumption that summative assessment somehow capture th culm ion of the learning process, at least as it is defined by a given curriculum. Fro a our perspect, there is no reason why even assessments administered at the end of a urse o rooram could not be forward-looking and thus promote development. In other words en our leoretical framework, assessing without mediation is problematic becaus leaves $\mathrm{p}$. $\mathrm{t}$ of the picture - the future - and it is difficult to imagine an ass smen con-tex at is not interested in the future (for additional discussion of this imp ant of stua nas traditionally been used to gather (Kristen Nielsen, 2012):

"informat which will inform teachers and students about the degree of success of their respective efforts in the classroom. It allows teachers to diagnose students' strengths and weaknesses in relation to specific curricular objectives and thus guides them in organizing and structuring instructional material".

(d'Anglejan et al., 1990: 107)

Based on a series of teacher interviews, Rea-Dickins and Gardner (2000: 229-30) conclude that FA serves teachers in four different ways: it helps them plan and manage their teaching; it provides evidence of student learning; it indexes the extent to which they and 
their students have attained what has been prescribed in the curriculum; and it provides them with evidence for evaluating their own teaching. Despite the perceived benefit of FA, ReaDickins and Gardner (2000: 231) express concerns about its validity and appropriateness, particularly because as a knowledge base, FA has remained an informal procedure rather than being systematically integrated into the curriculum and classroom practices. In addition, FA might also serve to motivate learners by providing them with feedback about what they can already do and what still needs improvement (Vandergrift and Bélanger, 1998: 572).

According to Rea-Dickins and Gardner (2000: 215), although researchers and educators have for some time acknowledged 'the pedagogical function of assessment', an insufficient amount of detailed research has been conducted on this topic. Moreover, Dann 2002 . points out that even in the general assessment literature, where a fair amount research $h$ been conducted on FA, focus has been on 'the ways in which teachers have th to infor their own practice so that pupils' needs are more specifically met' and much less tent on has been paid to 'the ways in which pupils participate in this process'

This is an important area for classroom research to address b au Rea-D ckinsand Gardner (2000: 237) caution, despite assumptions to the contr ry, class $n$ as essment is not necessarily low-stakes: high-stakes decisions are often pr ated on ners' in class performance. The problem is that because it is generally in rmal unsystematic, FA may either over or underestimates learner ability and prosess, res $g$ in inappropriate instruction or no instruction at all when it is in fact re fuired (2000: 238\%.

\section{CONCLOSUION}

In this paper we investigated different eores égarding to DA and ZPD. We draw the conclusion that Vygotsky as the forerunn of the field of ZPD didn't introduce us with he concept of the DA but in its place did a t by introducing the concept of ZPD that is an umbrella term for the otb rms wuch as DA and FA. The pedagogical aspects of this paper can all be mentione have much more prosp us classe. that students have also much more opportunities to learn and to manife th arning. I) concept of FA (Formative Assessment) is another path to know ab tifferent learning. In its ground, FA has introduced some alternative met ds of assessing adents in which the process of learning can be manifested in a more cl way s an example, portfolio is one of alternative methods of taching and assessing writ Correct e Feedback is another concept in which ZPD has played a great role. $G$ or $n$ ivin corrective feedback is a hot debate in progress that confused lots of $j$ struct s due th ne fact of different skills. According to all those conducted research onc oul the giving corrective feedback in different skills shoud be consia as an instructor in L2 teaching context.

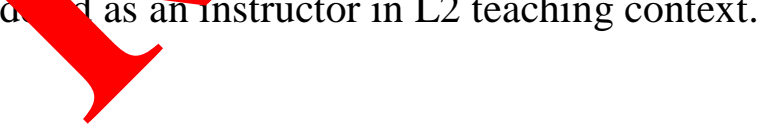




\section{References}

[1] Ableeva R. (2008). The effects of dynamic assessment on L2 listening. In J.P. Lantolf and M. Ein.

[2] Poehner (Eds.), Sociocultural theory and the teaching of second languages (pp. 57-86). London: Equinox.

[3] Carroll S., Swain M., Studies in Second Language Acquisition 15 (1993) 357-8

[4] Davydov V. V. (2004). Problems of developmental instruction: A theoret al and experimental study. Translated by P. Moxhay. Moscow: Akademiya Press.

[5] Ellis R. (2008). The study of second language acquisition. 2nd edition. Jxfor - Oxfo University Press.

[6] R. L. Falik, Rand Y., Feuerstein R. S. (2003). Dynamic asse sment modifiability. Jerusalem: ICELP Press.

[7] Feuerstein R., Miller R., Rand Y., Jensen M. R., The J al of cial Education 15 (1981) 201-19.

[8] Gass S. M., Mackey A. (2007). Input, interactio and output in second language acquisition.

[9] Gibbons P., TESOL Quarterly 37 (2002) 247-73.

[10] Haywood H. C., Lidz C. S. (2007). Dy, tmo acsment in practice. Clinical and educational applications. New York: Ca n ídge university Press.

[11] Monirosadat Hosseini, et a , In ationa Letters of Social and Humanistic Sciences 6 (2013) 1-12

[12] Hussein Meihami, I cermatio, Letters of Social and Humanistic Sciences 8 (2013) 8-23.

[13] Hussein Meiha i, Im ational Letters of Social and Humanistic Sciences 8 (2013) 24-33.

[14] Husseir Meihas Bahran Meihami, Zeinab Varmaghani, International Letters of Social a, Hanist Sciences 8 (2013) 57-65.

[15] $y$ in A., dis (2007). Sociocultural theory and education of children with speci needs: 10 m defectology to remedial pedagogy. In H. Daniels, M. Cole, \& J.V. , The Cambridge companion to Vygotsky (pp. 332-61). Cambridge: a bridge University Press.

[16] Lanto J. P. (2010). Sociocultural theory and the pedagogical imperative. In R.B. Kaplan (Ed.), The Oxford handbook of applied linguistics (pp. 163-77). 2nd edition. New York: Oxford University Press.

[17] Lantolf J. P., Poehner M. E. (2007). Dynamic assessment. In E. Shohamy (Ed.) \& N. Hornberger (Gen. Ed.), Encylopedia of language and education: Volume 7. Language testing and assessment (pp. 273-85).

[18] Poehner M. E. (2008). Dynamic assessment: A Vygotskian approach to understanding and promoting second language development. 
[19] Valsiner J., van der Veer R. (1993). The encoding of distance: The concept of the zone of proximal development and its interpretations. In R.R. Cocking and K.A. Renninger (Eds.), The development and meaning of psychological distance. Hillsdale, NJ: Lawrence Erlbaum.

[20] Vygotsky L. S. (1933). Dinamika umstvennogo razvitija shkol'nika v svjazi sobucheniem [The dynamics of intellectual development in school children as a result of teaching/learning].

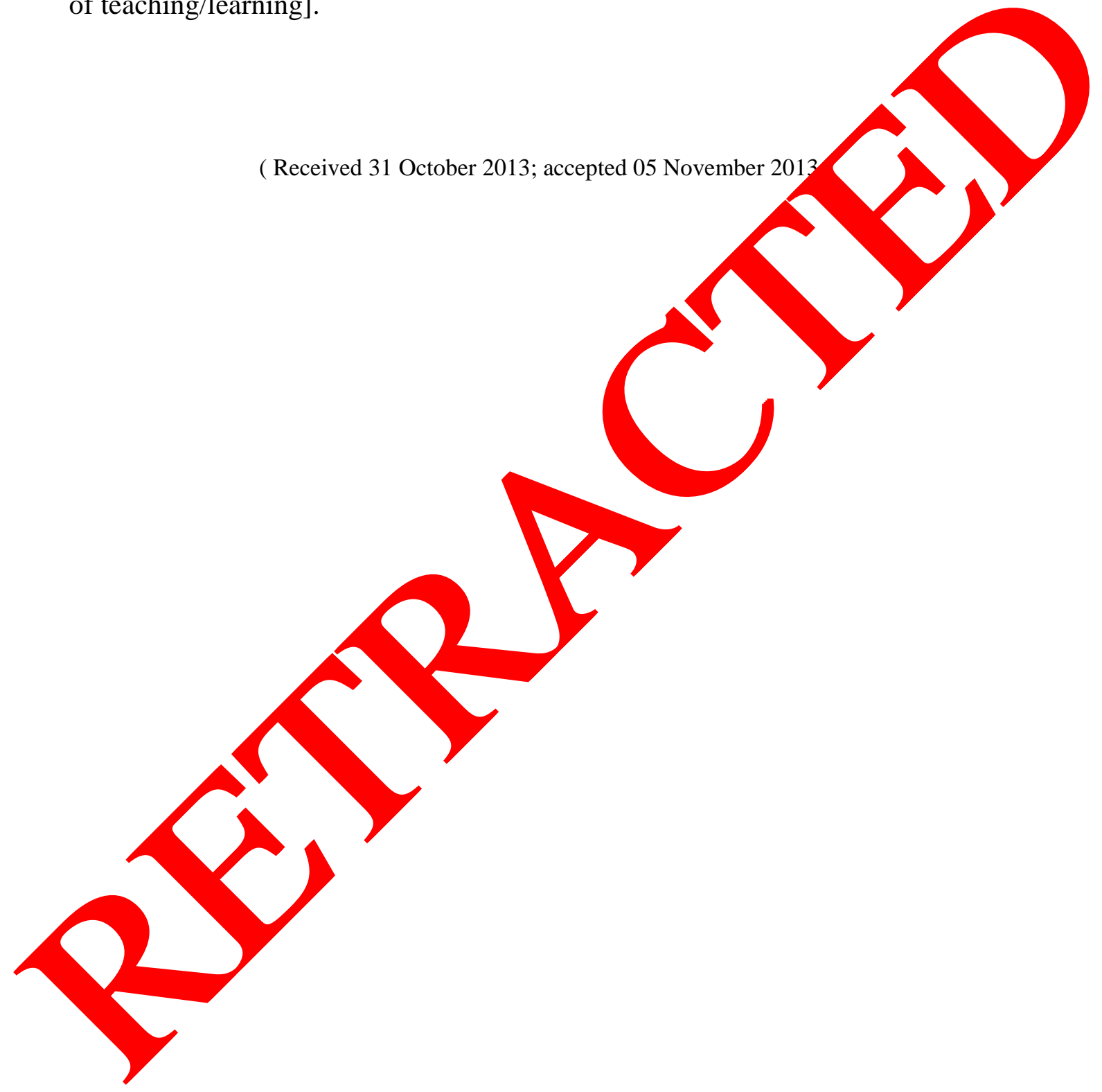

